\title{
Palm Ash as an Alternative Source for Silica Production
}

\author{
Faizul Che $\mathrm{Pa}^{1, *}$, Abdullah Chik ${ }^{1}$, and Md. Fazlul Bari ${ }^{1}$ \\ ${ }^{1}$ Centre of Excellence Geopolymer \& Green Technology, \\ School of Materials Engineering, Universiti Malaysia Perlis, \\ P.O Box 77, D/A Pejabat Pos Besar, 01007 Kangar, Perlis, Malaysia.
}

\begin{abstract}
Agricultural wastes such as palm ash and rice husk have a possibility to be used as a useful renewable source for the production of silica $\left(\mathrm{SiO}_{2}\right)$. Extensive researches have been carried out to extract silica from agricultural wastes such as rice husk, due to silica as a useful raw material for industrial application. In this study, the environmentally benign and economically effective process to produce $\mathrm{SiO}_{2}$ materials from palm ash has been established by using citric acid leaching, not the conventional strong acids. Results showed that silica can be extracted from palm ash using the citric acid leaching method under the optimum extracting conditions with $700{ }^{\circ} \mathrm{C}$ of solution temperature, 60 minutes of reaction time and concentration of citric acid of more than $2 \%$. The purity of silica extracted is more than $90 \%$.
\end{abstract}

\section{Introduction}

Silica is one of the basic materials \& the valuable inorganic multipurpose chemical compounds. Silica is occurring naturally as quartz, sand or flint. It can exist in gel, crystalline \& amorphous forms. Nowadays, most silica was produced from quartz or sand by the extraction process. Sodium silicate, the precursor for silica production is currently manufactured by smelting quartz sand with sodium carbonate at $1300{ }^{\circ} \mathrm{C}$ [1]. However, manufacturing of high purity silica is energy intensive. Silica also can be found in agricultural wastes such as palm ash \& rice husk.

Extensive researches have been carried out to extract silica from agricultural wastes. Leaching is a proper route to extract the silica. Leaching generally refers to the removal of a substance from a solid via a liquid extraction media. The desired component diffuses into the solvent from its natural solid form. The temperature, contact time and solvent selection are three important parameters in leaching process. The temperature can be adjusted to optimized solubility and mass transfer [2-5].

Organic acid is an alternative chemical to replace the strong acid in the leaching process. This is because the organic acid has low level of hazardous compared to the strong acid. Researchers all over the world are focusing on ways to establish an environmentally

\footnotetext{
*Corresponding author: faizul@unimap.edu.my
} 
benign process to produce silica from agricultural wastes by using organic acid rather than using strong acid.

\section{Materials And Method}

\subsection{Palm Ash}

Palm oil is an important export commodity in tropical countries and especially in Malaysia due to its wide spectrum of an acknowledged usability such as precursors of food products and biofuel. Extraction of the oil from fresh oil palm fruitlets requires separation of the fruitlets from empty fruit bunches prior to further processing. These empty fruit bunches, which consists of fibres and shells, are often used as boiler fuel by palm oil mills to produce steam for electricity generation and palm oil extraction. Combustion produces approximately $5 \%$ of palm ash [6]. Because of limited uses for palm ash, it is currently disposed of as landfill; this could lead to environmental problems in the future. Palm ash has about $46.0 \%$ silicon element. It is possible to extract silica from palm ash.

\subsection{Leaching Process}

Palm ash from local palm oil mill was used as raw materials to produce silica materials. Citric acid powders were dissolved in the distilled water at the ambient temperature to prepare citric acid solutions. 10 to $30 \mathrm{~g}$ palm ash (having a mean particle size of $75 \mu \mathrm{m}$ ) was put into $500 \mathrm{ml}$ citric acid solution in the beaker. Due to the chelate reaction between$\mathrm{COOH}$ groups and metallic impurities strongly depend on The concentration and temperature of the citric acid solution, and stirring time in the solution were selected as the operating parameters. The concentration was controlled from 1 to $6 \%$ by changing the mixing ratio of citric acid powders and distilled water. The beaker was placed on the hot plate magnetic stirrer, and the solution temperature was changed from 30 to $70{ }^{\circ} \mathrm{C}$. The reaction time recorded was 30 to 90 minutes. After the acid leaching process, the water rinsing treatment of the palm ash was carried out with the distilled water at room temperature to remove the citric acid content of the ash. The materials were dried at $60{ }^{\circ} \mathrm{C}$ for $60 \mathrm{~min}$ in the oven, and then combusted at $800{ }^{\circ} \mathrm{C}$ for $30 \mathrm{~min}$ in the tube furnace. The combustion temperature of $800{ }^{\circ} \mathrm{C}$ was used in this study to prevent the crystallization of amorphous silica contained in the ash [5,7].

\section{Result And Discussion}

In hydrometallurgical extraction, many leaching agents are used such as $\mathrm{HCl}, \mathrm{HNO}_{3}$ and $\mathrm{H}_{2} \mathrm{SO}_{4}$. However, most of these leachants cause environmental pollutions. Organic acids such as citric, acetic or oxalic acids can be attractive leaching agents as the leaching is carried out at moderate acidic conditions [8].

\subsection{Palm Ash}

Photographs of the as-received palm ash and pulverized palm ash samples obtained from the local oil palm company are shown in Figure 1. The colour of pulverised palm ash used to be dark grey. 

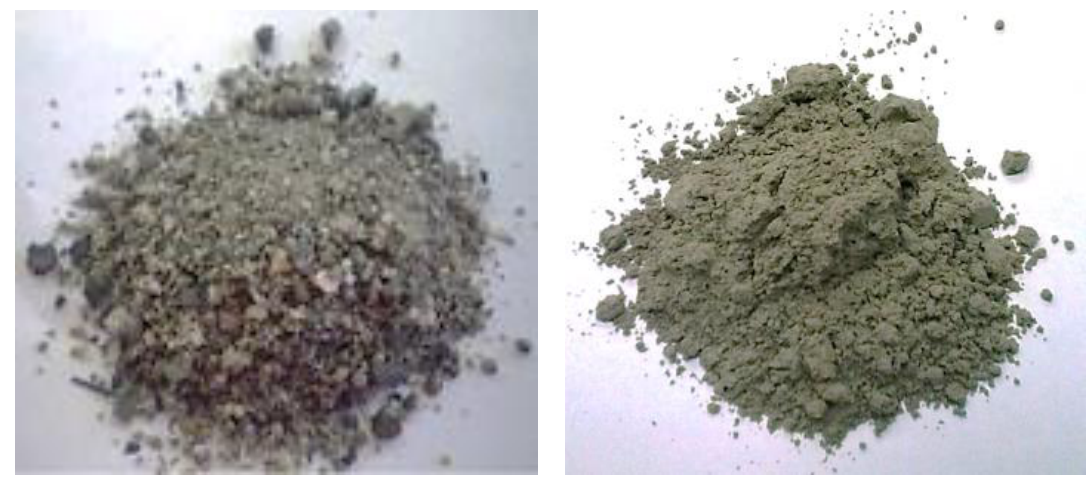

Fig. 1. Digital photo of (left) as-received palm ash (right) pulverized palm ash

Typically, palm ash is characterized by a spongy and porous structure in nature, its main components are in the angular and irregular form with a sizable fraction showing cellular textures. The scanning electron microscope (SEM) images (Figure 2) revealed that palm ash used has medium-sized particles with crushed shape structure. The main components of palm ash are the oxides of $\mathrm{Si}, \mathrm{Al}$ and various metallic oxides. Energy dispersive X-ray spectroscopy (EDX) analysis (Figure 3) confirms the presence of Si and Al.

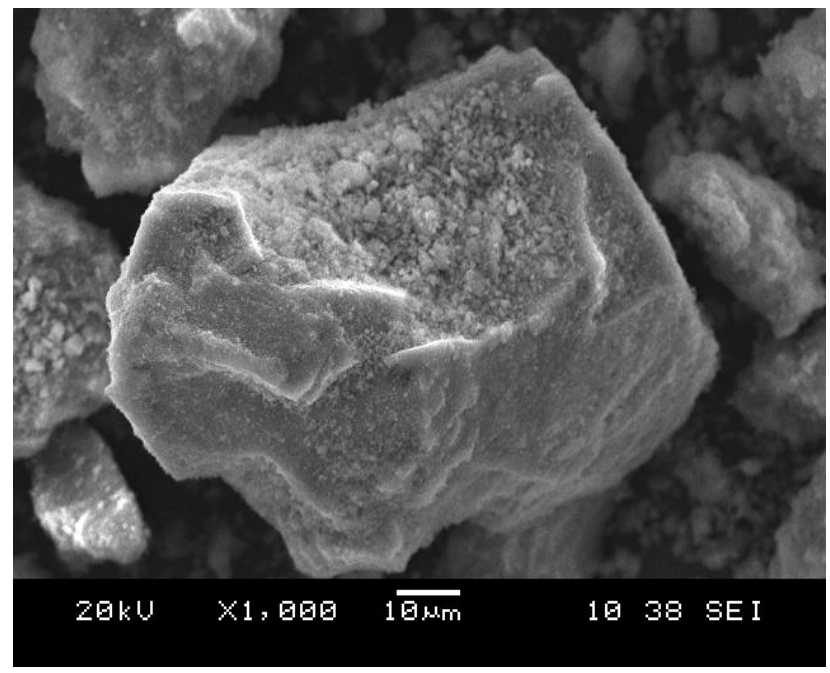

Fig. 2. SEM images of ground palm. 


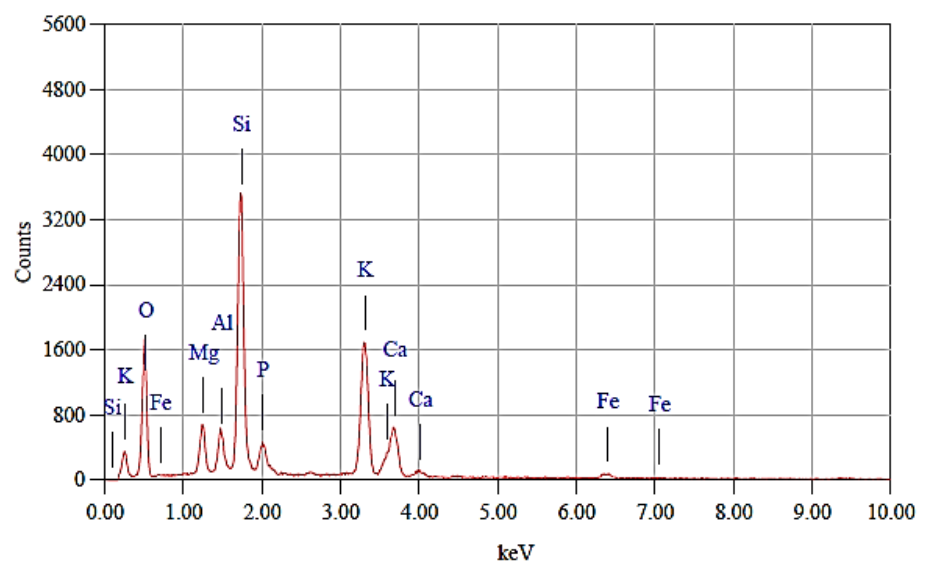

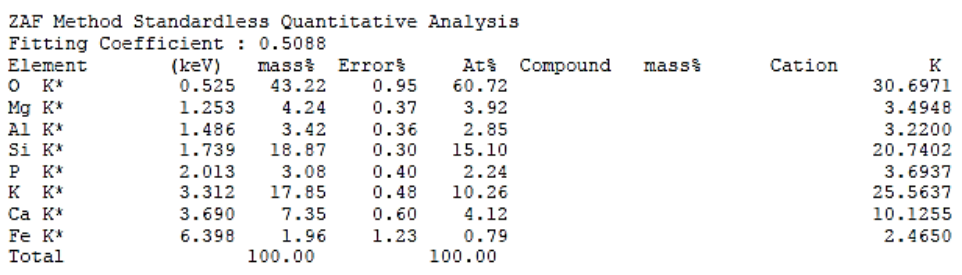

Fig. 3. EDX result of ground palm ash.

The X-ray powder diffraction (XRD) pattern (Figure 4) indicated that a high intensity peak was observed at $26.7^{\circ}(2 \theta)$ corresponding to the quartz present in palm ash used in this research, while the low intensity peaks can be assigned to other oxides present in the palm ash. An amorphous hump was observed between $30^{\circ}$ and $35^{\circ}$, this may be due to the presence of amorphous glassy material [9]. A high intensity peak was observed at $22.5^{\circ}$ corresponding to the silicates present in both forms of palm ash while the low intensity peaks can be assigned to other metal oxides present in the palm ash [10]. Phase analysis by x-ray diffraction shows that quartz $\left(\mathrm{SiO}_{2} ;\right)$, calcite $\left(\mathrm{CaCO}_{3}\right)$ and kalsilite $\left(\mathrm{KAlSiO}_{4}\right)$ in palm ash mainly exists as crystalline substance.

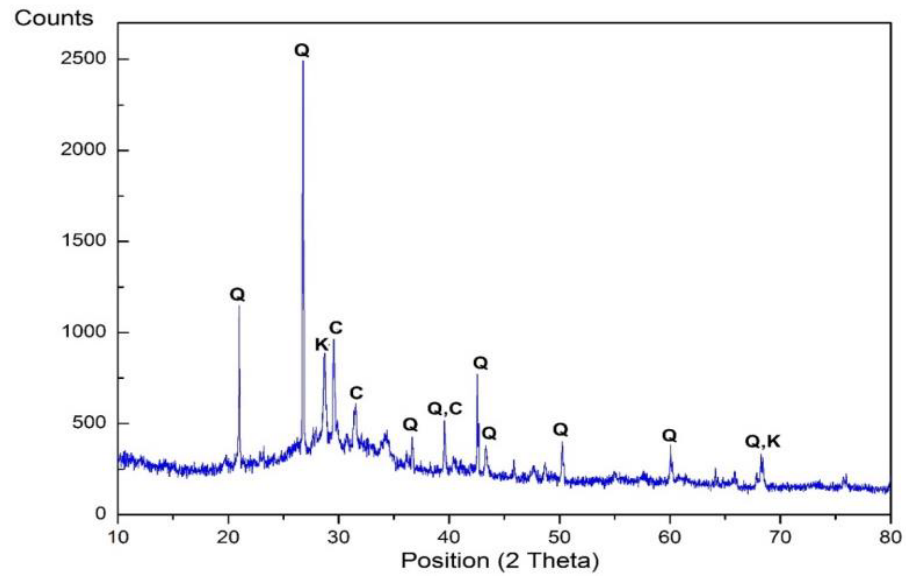

Fig. 4. $\mathrm{XRD}$ pattern of the palm ash. $\mathrm{Q}=\mathrm{SiO}_{2}, \mathrm{C}=\mathrm{CaCO}_{3}, \mathrm{~K}=\mathrm{KalSiO}_{4}$. 
The present of different elements concentration in palm ash is affected by the area of plantation, geographical distribution, quantity of fertilizers used, and agronomy used for the growth of palm ash [11].

\subsection{Effect of Acid Concentration.}

In general, the $\mathrm{SiO}_{2}$ content increases with increasing acid concentration. The purity of silica $\left(\mathrm{SiO}_{2}\right)$ dramatically increased from just $45.5 \%$ in palm ash up to $92 \%$ when employing the citric acid solution with a concentration of $2 \%$ and higher (Table 1).

Table 1. Chemical compositions of palm ash via the citric acid solution leaching treatment obtained at various concentrations.

\begin{tabular}{|c|c|c|c|c|c|c|c|}
\hline $\begin{array}{c}\text { Acid } \\
\text { Concentration } \\
\text { (\%) }\end{array}$ & $\mathbf{S i O}_{\mathbf{2}}$ & $\mathbf{M g O}$ & $\mathbf{A l}_{2} \mathbf{O}_{\mathbf{3}}$ & $\mathbf{P}_{\mathbf{2}} \mathbf{O}_{\mathbf{5}}$ & $\mathbf{K}_{\mathbf{2}} \mathbf{O}$ & $\mathbf{C a O}$ & $\mathbf{F e}_{\mathbf{2}} \mathbf{O}_{\mathbf{3}}$ \\
\hline Palm Ash & 45.50 & 3.20 & 5.40 & 5.38 & 23.30 & 12.80 & 3.26 \\
\hline 1 & 66.70 & 6.00 & - & 2.88 & 12.00 & 6.62 & 4.10 \\
\hline 2 & 89.00 & 1.00 & - & - & 4.22 & 1.30 & 2.55 \\
\hline 3 & 92.00 & - & - & - & 3.58 & 1.22 & 2.13 \\
\hline 4 & 92.00 & - & - & - & 3.56 & 0.85 & 3.07 \\
\hline 5 & 92.00 & - & - & - & 3.54 & 0.80 & 2.97 \\
\hline 6 & 92.00 & - & - & - & 2.84 & 1.00 & 2.53 \\
\hline
\end{tabular}

The content of metal oxide impurities also reduced when the concentration of the solution was increased. It means the use of the citric acid leaching treatment obviously caused the reduction of the total content of metal oxide impurities and resulted in a highpurification of silica materials contained in the palm ash. Concerning the content of metal elements remained in the ashes, the use of citric acid solution is remarkably effective to reduce them.

In particular, $\mathrm{Al}_{2} \mathrm{O}_{3}$ has been completely removed from the palm ash by using the citric acid solution leaching with $1 \%$ or more concentration, while $\mathrm{P}_{2} \mathrm{O}_{5}$ has been totally taken away from the palm ash using $2 \%$ of citric acid solution. Furthermore, it is obvious that the citric acid solution leaching treatment is also effective in removing $\mathrm{K}$ and $\mathrm{Ca}$ elements from palm ash. The content of $\mathrm{K}_{2} \mathrm{O}$ and $\mathrm{CaO}$ extremely reduced and the reduction rate is $48.5-$ $87.8 \%$ and $48.3-93.8 \%$ respectively by comparing the remained content of palm ash before and after citric acid solution leaching treatment. The content of $\mathrm{MgO}$ in palm ash, even so, was entirely removed with concentration of $3 \%$ and higher.

Thus, it shows that citric acid leaching treatment is significantly useful and effective to remove impurities and increased the purity of silica in palm ash. Organic acids such as citric acid have carboxyl groups and therefore can act as chelating agents. These carboxyl groups, tend to donate protons $(\mathrm{H}+)$, resulting in the negatively charged carboxyl group that is capable of forming stable complexes with several metal ions. The impurities were removed from the ash via chelate reaction between carboxyl groups $(-\mathrm{CHOOH})$ and the metal elements [2-5]. Therefore, it is possible that these negatively charged carboxyl groups are able to form stable complexes with $\mathrm{Ca}+$ and $\mathrm{K}+$ cations present, resulting in their removal from the palm ash. 


\subsection{Effect of Reaction Temperature}

The use of high temperatures can lead to an increase in the leaching performance as shown in Table 2.

Table 2. Chemical composition of treated palm ash via citric acid solution treatment obtained at various reaction temperatures.

\begin{tabular}{|c|c|c|c|c|c|c|c|c|}
\hline $\begin{array}{c}\text { Solution } \\
\text { Temp. } \\
\left({ }^{\mathbf{0}} \mathbf{C}\right)\end{array}$ & $\begin{array}{c}\text { Acid } \\
\text { Conc. } \\
\mathbf{( \% )}\end{array}$ & $\mathbf{S i O}_{\mathbf{2}}$ & $\mathbf{M g O}$ & $\mathbf{A l}_{\mathbf{2}} \mathbf{O}_{\mathbf{3}}$ & $\mathbf{P}_{\mathbf{2}} \mathbf{O}_{\mathbf{5}}$ & $\mathbf{K}_{\mathbf{2}} \mathbf{O}$ & $\mathbf{C a O}$ & $\mathbf{F e}_{\mathbf{2}} \mathbf{O}_{\mathbf{3}}$ \\
\hline $\begin{array}{c}\text { Palm } \\
\text { Ash }\end{array}$ & - & 45.50 & 3.20 & 5.40 & 5.38 & 23.30 & 12.80 & 3.26 \\
\hline 30 & 3 & 87.00 & 1.80 & - & - & 4.96 & 1.35 & 2.78 \\
\hline 50 & 3 & 90.00 & 1.20 & - & - & 4.17 & 1.07 & 2.43 \\
\hline 70 & 3 & 92.00 & - & - & - & 3.58 & 1.22 & 2.13 \\
\hline 90 & 3 & 92.13 & - & - & - & 3.50 & 1.19 & 2.07 \\
\hline 30 & 2 & 83.00 & 2.20 & - & - & 6.18 & 1.73 & 3.36 \\
\hline 50 & 2 & 87.00 & 2.00 & - & - & 4.90 & 1.44 & 3.18 \\
\hline 70 & 2 & 89.00 & 1.00 & - & - & 4.22 & 1.30 & 2.55 \\
\hline 90 & 2 & 88.00 & 1.10 & - & - & 4.87 & 1.38 & 2.82 \\
\hline
\end{tabular}

With increased in the temperature, most of the impurities are decreased and the purification of silica increased up to $92 \%$ takes place after leaching at $70{ }^{\circ} \mathrm{C}$. In the case of $\mathrm{Al}_{2} \mathrm{O}_{3}$ and $\mathrm{P}_{2} \mathrm{O}_{5}$, even the temperature of $30{ }^{\circ} \mathrm{C}$ and $2 \%$ citric acid concentration leaching treatment is enough to remove $\mathrm{Al}$ and $\mathrm{P}$ impurities in palm ash. While $\mathrm{MgO}$ content of the ashes was fully taken out of palm ashes at a temperature of $70{ }^{\circ} \mathrm{C}$ and $3 \%$ citric acid concentration. On the other hand, other impurity elements such as $\mathrm{K}, \mathrm{Ca}$ and $\mathrm{Fe}$ discharged into the acid solution during the acid leaching process gradually increase with increasing the reaction temperature.

An increase in temperature of leaching treatment process speeds up the chemical reaction. The rising temperature will be affected on kinetic energy to molecules. The molecule will move faster, collide more frequently and causing the reaction rate of temperature in the general to increase. It indicates that using higher temperature in the process will improve the leaching result. The palm ash used in this research work has been pulverised to increase the leaching rate. Theoretically, the smaller size of the material, the easier to be heated and mass transfer, the higher leaching rate [12].

The use of high temperatures can lead to an increase in the leaching performance, but the use of high temperatures may be limited with organic acids due to their low boiling temperatures and decompositions [13]. Higher temperature tends to vaporize organic acids and water and contaminates the vapour phase stream with mainly carbon dioxide [13]. Higher temperatures tend to decrease the solubility of the reaction by-products in water and it makes the separation difficult. Furthermore, in the industrial processes at relatively higher temperatures, organic acids may cause a little corrosive effect.

\subsection{Effect of Reaction Time}

The purity of silica increased with the increasing of reaction time as shown in Table $3 . \mathrm{SiO}_{2}$ content in palm ash increased dramatically from $45.5 \%$ to $87.0 \%$ after 30 minutes leaching process. When the reaction time increased from 30 minutes to 60 minutes, the purity of silica slightly increased by about $5 \%$. However, no significant increase in silica purity was 
observed at a longer reaction time than 60 minutes. Beyond this range the effect is negligible, so the reaction time of 60 minutes was confirmed to be the optimal reaction time. Other investigators observed the value ranges from 45 to $60 \mathrm{~min}$ for effective dissolution [13].

Table 3. Chemical composition (\%) of palm ash after citric acid solution treatment obtained at various reaction times.

\begin{tabular}{|c|c|c|c|c|c|c|c|}
\hline $\begin{array}{c}\text { Reaction } \\
\text { Time } \\
\text { (minute) }\end{array}$ & $\mathbf{S i O}_{\mathbf{2}}$ & $\mathbf{M g O}$ & $\mathbf{A l}_{\mathbf{2}} \mathbf{O}_{\mathbf{3}}$ & $\mathbf{P}_{\mathbf{2}} \mathbf{O}_{\mathbf{5}}$ & $\mathbf{K}_{\mathbf{2}} \mathbf{O}$ & $\mathbf{C a O}$ & $\mathbf{F e}_{\mathbf{2}} \mathbf{O}_{\mathbf{3}}$ \\
\hline $\begin{array}{c}\text { Palm } \\
\text { Ash }\end{array}$ & 45.50 & 3.20 & 5.40 & 5.38 & 23.30 & 12.80 & 3.26 \\
\hline 30 & 87.00 & 1.50 & - & - & 5.68 & 1.49 & 2.65 \\
\hline 60 & 92.00 & - & - & - & 3.58 & 1.22 & 2.13 \\
\hline 90 & 92.00 & - & - & - & 3.25 & 1.16 & 2.22 \\
\hline 120 & 92.30 & - & - & - & 3.01 & 0.99 & 2.37 \\
\hline 180 & 92.40 & - & - & - & 2.90 & 0.82 & 2.43 \\
\hline
\end{tabular}

Studies done by Ukiwe and Luke [14] appears to suggest that organic acids such as citric and oxalic acids seemed to be more promising as chemical extracting agents for removal of heavy metal from sludge at contact time of 60 minutes, since these acids are biodegradable and can attain a higher metal extraction efficiency at this contact time compared to other contact times.

\subsection{Effect of Solid/liquid Ratio.}

Table 4 shows that in the leaching process, lower solid/liquid ratios (0.02:1 and 0.04:1) lead to achieving the higher purity of silica. The silica content in treated palm ash was raised by up to $92 \%$. When the solid/liquid was increased from 0.04:1 to $0.06: 1$ until 0.10:1, with the other conditions unchanged, the purity of silica content in treating palm ash decreased to $83 \%$.

Table 4. Chemical composition (\%) of palm ash after citric acid solution treatment obtained at various solid/liquid ratio.

\begin{tabular}{|c|c|c|c|c|c|c|c|}
\hline $\begin{array}{c}\text { Solid/liquid } \\
\text { Ratio }\end{array}$ & $\mathbf{S i O}_{\mathbf{2}}$ & $\mathbf{M g O}$ & $\mathrm{Al}_{\mathbf{2}} \mathbf{O}_{\mathbf{3}}$ & $\mathbf{P}_{\mathbf{2}} \mathbf{O}_{\mathbf{5}}$ & $\mathbf{K}_{\mathbf{2}} \mathbf{O}$ & $\mathbf{C a O}$ & $\mathbf{F e}_{\mathbf{2}} \mathbf{O}_{\mathbf{3}}$ \\
\hline Palm Ash & 45.50 & 3.20 & 5.40 & 5.38 & 23.30 & 12.80 & 3.26 \\
\hline $0.02: 1$ & 91.00 & - & - & - & 3.76 & 0.96 & 2.86 \\
\hline $0.04: 1$ & 92.00 & - & - & - & 3.58 & 1.22 & 2.13 \\
\hline $0.06: 1$ & 87.00 & - & - & - & 5.28 & 3.59 & 2.65 \\
\hline $0.08: 1$ & 85.00 & - & - & - & 5.61 & 4.51 & 3.71 \\
\hline $0.10: 1$ & 83.00 & - & - & - & 6.05 & 4.98 & 3.64 \\
\hline
\end{tabular}

Table 4 shows that the contents of $\mathrm{K}_{2} \mathrm{O}$ and $\mathrm{CaO}$ in treated palm ash were decreased up to $84.6 \%$ and $92.5 \%$, respectively, when the solid/liquid ratios were $0.04: 1$ and below. When the solid/liquid ratio increased to $0.10: 1$, the contents of $\mathrm{K}_{2} \mathrm{O}$ and $\mathrm{CaO}$ were 
decreased only about $74.0 \%$ and $61.0 \%$, respectively. It happens because of not enough of carboxyl groups $(-\mathrm{CHOOH})$ that act as chelating agents to promote stable complexes with $\mathrm{Ca}+$ and $\mathrm{K}+$ cations present in palm ash. The impurities were removed from the ash via chelate reaction between carboxyl groups and the metal elements [2-5].

The limitations associated with the poor dissolution of metal elements by citric acid at the solid/liquid ratio higher than $0.04: 1$, indicate a lower purity of silica. A solid/liquid ratio $0.04: 1$ by using $3 \%$ citric acid was found to be the most promising and suitable condition to produce high purity of silica from palm ash.

\subsection{Comparison between Organic Acid and Strong Acid}

Hydrochloric acid solution is also used as the comparison in the leaching treatment. 1, 2, 3 and $4 \%$ of hydrochloric acid and citric acid solution was used in this study. The reaction temperature was controlled at $70{ }^{\circ} \mathrm{C}$ and 60 minutes reaction time. Figure 4 shows that the content of silica in palm ash treated with hydrochloric acid was much higher than silica content in palm ash treated with citric acid.

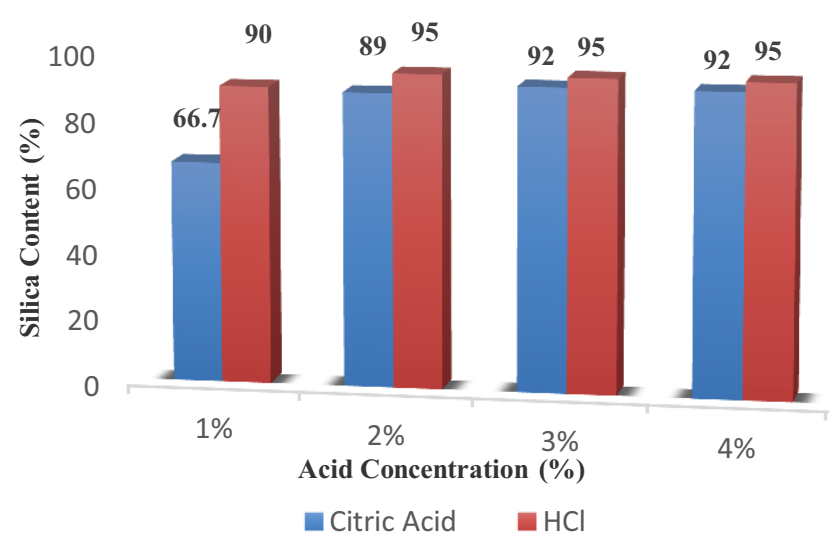

Fig. 4. Silica content (\%) versus acid concentration

Two factors, mainly account; type of acid used in the leaching process \& carbon content in palm ash. The strong acid almost fully ionized when mixed with water to produce hydrogen ions from water, whereas organic acid only partially dissociate into ions and leaving an increasing percentage of untreated molecules in the solution. In the leaching process, $\mathrm{H}+$ ion should be the unique responsible for the dissolution reaction [8]. Anions such as $\mathrm{NO}^{3-}, \mathrm{SO}_{4}{ }^{2-}$ and $\mathrm{Cl}-$ should be non-effective. However, it is worth noting that inorganic acids completely dissolved in water, which means in case $\mathrm{HCl}$ and $\mathrm{HNO}_{3}$ that the same mol number of $\mathrm{H}+$ were present in the solution leading normally to the same

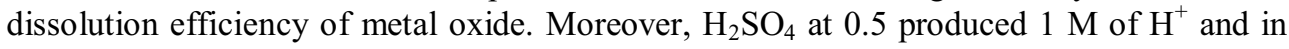
spite of that, lower dissolution efficiency of $\mathrm{H}_{2} \mathrm{SO}_{4}$ was observed compared to $\mathrm{HCl}$. These results indicate that leaching is not a simple process and that anions may play an important role in the rate of metal oxide dissolution [8].

It is reported in Table 1 that metal impurities such as $\mathrm{K}$ and $\mathrm{Ca}$ are included in palm ash. These metal impurities cause the remained carbons in ashes, which are originated in palm ash. As mentioned before, palm ash is a by-product from burning process in palm oil plantation, which palm shell, fibre and empty fruit bunches of palm burn at a temperature 
about $800-1000^{\circ} \mathrm{C}$. The eutectic reaction between the metals and $\mathrm{SiO}_{2}$ element occurs in the burning process of palm ash, and the carbon remains in the melts $\mathrm{SiO}_{2}$ [2-5]. Once carbon is entrapped in these melt, it cannot be easily removed because of the intimate contact between silica and carbon in palm ash (some of the silica might also be bonded to the organic compound in palm ash) [15]. XRD patterns of treated palm ash (Figure 5) show that carbon still exists after treated the palm ash with 2-3\% citric acid at a solution temperature of $70{ }^{\circ} \mathrm{C}$ for 60 minutes.

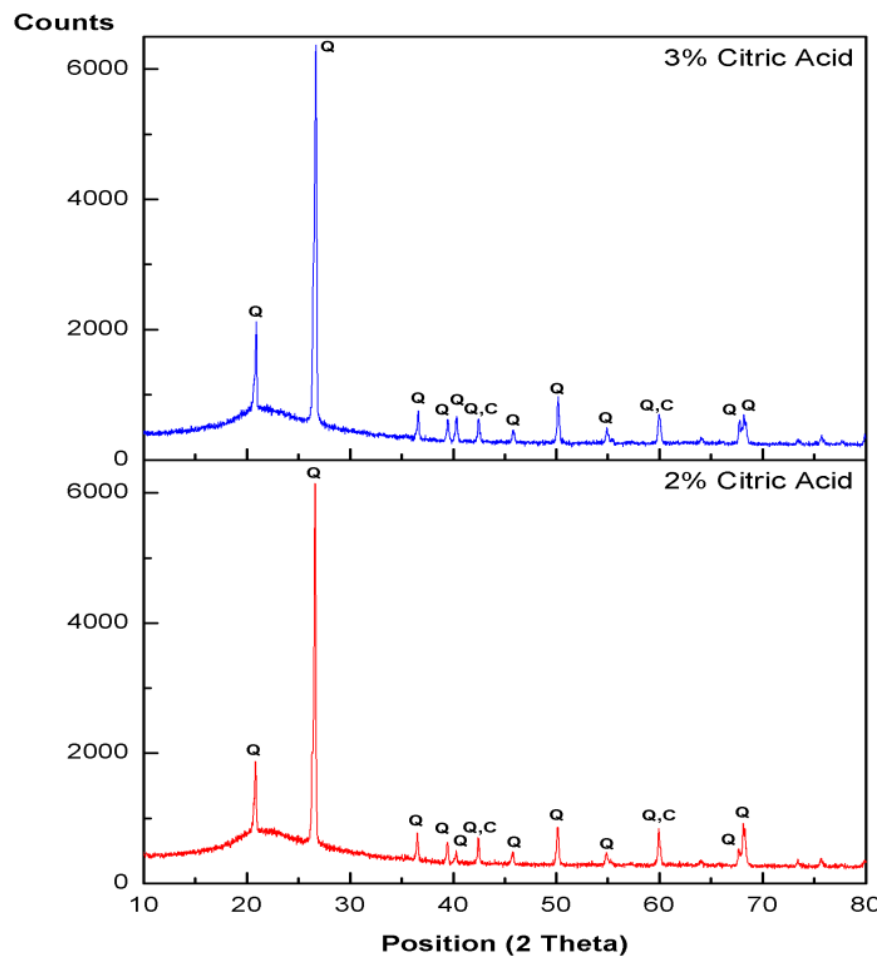

Fig. 5. XRD Pattern Of The Treated Palm Ash. $\mathrm{Q}=\mathrm{SIO}_{2}, \mathrm{C}=\mathrm{CARBON}$.

\section{Conclusion}

It was possible to obtain silica from palm ash using the organic acid leaching method. It consists of a citric acid leaching and the combustion process. Citric acid leaching treatment is significantly useful and effective to remove the impurities and increased the purity of silica in palm ash.

The authors would like to thank the Center of Excellence Geopolymer \& Green Technology, School of Materials Engineering, Universiti Malaysia Perlis and Malaysian Government for financing this project through the Research Acculturation Collaborative Effort (RACE) grant scheme (9017-00011).

\section{References}

1. U. Kalapathy, A. Proctor, J. Shultz, Bioresour Techno., 73, 257 (2000)

2. J. Umeda, K. Kondoh, J. Mater. Sci., 43, 7084 (2008) 
3. J. Umeda, K. Kondoh, Trans. JWRI, 37, 13 (2008).

4. J. Umeda, H. Imai, K. Kondoh, Trans. JWRI, 38, 13 (2009)

5. J. Umeda, K. Kondoh, Ind. Crops. Prod., 32, 539 (2010)

6. C.P. Faizul, C. Abdullah, B. Fazlul, Adv. Mat. Res., 626, 997 (2013)

7. C.P. Faizul, C. Abdullah, B. M. Fazlul, Key Eng. Mater., 673, 13 (2016)

8. N. Habbache, N. Alane, S. Djerad, Tifouti, Chem. Eng. J., 152, 503 (2009)

9. P. J. Williams, J. J. Biernacki, C. J. Rawn, L. Walker, J. Bai, ACI Mater J. 102, 330 (2005)

10. N.F. Zainudin, K.T. Lee, A.H. Kamarudin, S. Bhatia, A.R. Mohamed, Sep. Purif Technol., 45, 50 (2005)

11. K.Y. Foo, B.H. Hameed, J. Hazard. Mater., 172, 523 (2009)

12. X. Fan, W. Xing, H. Dong, J. Zhao, Y. Wu, B. Li, W. Tong, X. Wu, Int. J. Nonferrous. Metall., 2, 63 (2013)

13. M. Gharabaghi, M. Irannajad, M. Noaparats, Hydrometallurgy, 103, 96 (2010)

14. N.U. Luke, I.I. Chinonye, Terr. Aquat. Environ. Toxicol., 5, 73 (2011)

15. S. Yafei, Z. Peito, S. Qinfu, Microporous Mesoporous Mater., 188, 46 (2014) 